\title{
Fatal post-viral neurodegenerative disorder
}

INSERM

\section{Source}

INSERM. (1999). Orphanet: an online rare disease and orphan drug data base. Fatal postviral neurodegenerative disorder. ORPHA:391343

Fatal post-viral neurodegenerative disorder is a rare neuroinflammatory disease characterized by the onset of ataxia, dysarthia and cerebral white matter changes which are triggered by viral infection. Episodic progressive neurodegeneration (manifesting with loss of motor and verbal skills, muscle weakness, further cerebral white matter degeneration and, eventually, death) is observed in the absence of hematopathology, cytokine overproduction, fever, hypertrig liceridemia, hypofibrinogenemia and hyperferritinemia. 